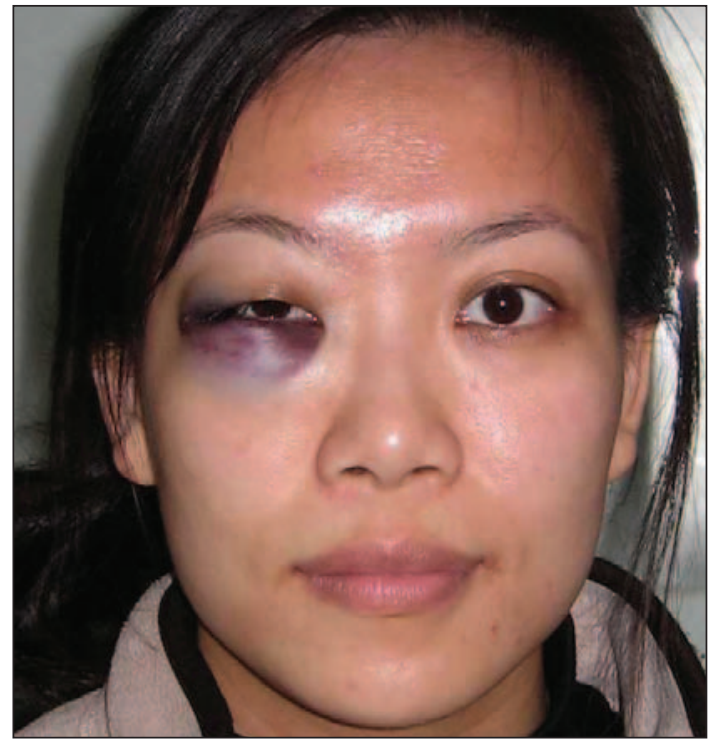

Figure 1: Swelling and ecchymosis in the right eye of a hyperbaric oxygen therapy technician.

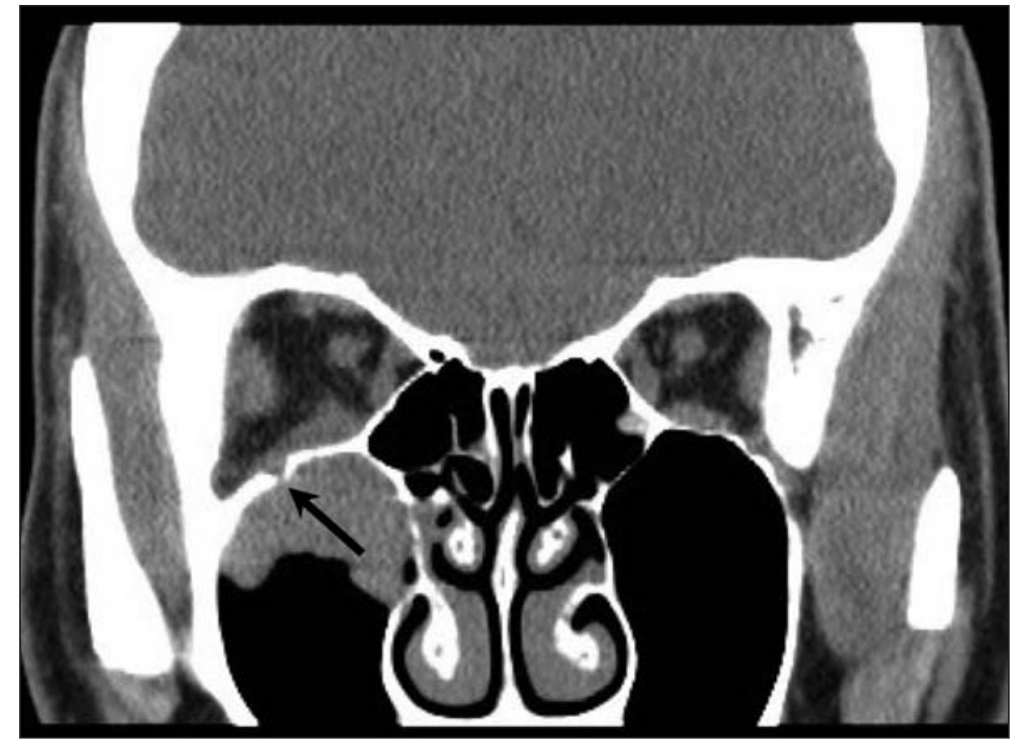

Figure 2: Computer tomography scan of the head in coronal view showing a fracture of the maxillary bone (arrow).

\title{
Fracture of the maxillary bone during hyperbaric oxygen therapy
}

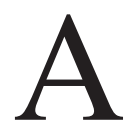

\section{$26-$} paranasal sinusitis was admitted to the emergency department because of ecchycompanied patients into the treatment chamber. She reported having worked when she had a cold 3 days before presenting to the emergency department. During decompression to 2.5 atmospheres, she felt discomfort under her right eye. Sudden, painful swelling and ecchymosis developed under her eye when the pressure was reduced to about 1.6 atmospheres (Figure 1). A computer tomography scan of the head in coronal view showed a fracture of her maxillary bone (Figure 2). She recovered uneventfully with supportive treatment.

Trauma of the paranasal sinuses is a rare complication of hyperbaric oxygen therapy. Infection of the upper respiratory tract is a relative contraindication for the procedure. Damage may occur to the maxillary division of the fifth cranial nerve, which passes through the sinus covered only by a mucous membrane. Other relative contraindications of hyperbaric oxygen therapy include fever, seizure disorders, emphysema with hypercapnia and untreated pneumothorax. ${ }^{1}$
Clinical images are chosen because they are particularly intriguing, classic or dramatic.

Submissions of clear, appropriately labelled high-resolution images must be accompanied by a figure caption and the patient's written consent for publication. A brief explanation (300 words maximum) of the educational significance of the images with minimal references is required.
Yi-Heng Liu MD

Te-Chun Hsia MD

Department of Internal Medicine

Juhn-Cherng Liu MD

Department of Radiology

Wei Chen MD

Department of Internal Medicine

China Medical University Hospital

Taichung, Taiwan

\section{REFERENCE}

1. Hamilton-Farrell M, Bhattacharyya A Barotrauma. Injury 2004:35:359-70. 